\title{
Injury to the Inferior Epigastric Artery Branch Necessitating Re-laparoscopy - An Unusual Cause of Bleeding in Laparoscopic Cholecystectomy
}

\section{Shresth Manglik ${ }^{1}$, Urmila Basu ${ }^{1 *}$, Camelia Pal $^{1}$, Pradeep Narayan ${ }^{2}$ and Sanjay Kumar Dubey ${ }^{3}$}

${ }^{1}$ Resident Department of General Surgery, Rabindranath Tagore International Institute of Cardiac Sciences, Kolkata, West Bengal, India

${ }^{2}$ Senior Consultant, Department of Cardiac Surgery, Rabindranath Tagore International Institute of Cardiac Sciences, Kolkata, West Bengal India

${ }^{3}$ Senior Consultant and Head - Department of General Surgery, Rabindranath Tagore International Institute of Cardiac Sciences, Kolkata, West Bengal, India

*Corresponding Author: Urmila Basu, Resident Department of General Surgery, Rabindranath Tagore International Institute of Cardiac Sciences, Kolkata, West Bengal, India.
Received: October 14, 2020

Published: December 10, 2020

(c) All rights are reserved by Urmila Basu., et al.

\begin{abstract}
Bleeding after laparoscopic cholecystectomy can be due to multiple reasons and can lead to significant morbidity and mortality, if not recognized and treated promptly. Bleeding from the cystic artery, ligaments of liver, or from the abdominal wall during the placement of ports are common sources of bleeding in these cases. Injury to the inferior epigastric artery and its branches are more common in gynecological and obstetric surgery and is infrequently reported after laparoscopic cholecystectomy. However, the course of inferior epigastric artery is extremely variable. In this report, we describe one such case that highlights the variability in the course of inferior epigastric artery making it vulnerable to injury.
\end{abstract}

Keywords: Laparoscopic Cholecystectomy; Bleeding; Cystic Artery

\section{Introduction}

Laparoscopic Cholecystectomy (LC) can be associated with significant morbidity due to intra and post operative hemorrhage. Bleeding can occur anytime during LC, particularly while creating pneumo-peritoneum, secondary port placement, during dissection, from the liver or due to slippage of clips/ligature in the post operative period. The incidence of bleeding in LC has been reported to be nearly $10 \%$ in various series ranging from minor hematoma to major bleeding from intra-abdominal vessels and are potentially lethal if not recognized and treated in time [1,2]. In this case we describe an injury to the inferior epigastric artery branch probably during specimen extraction which went unrecognized despite meticulous inspection of the port sites. Early recognition of the bleeding and prompt intervention led to uneventful recovery.

\section{Case Report}

A 40 year old patient with symptomatic gall stone disease and no other major co-morbidity underwent laparoscopic cholecystectomy.
Laparoscopic cholecystectomy was performed with standard 4 port technique after creating pneumo-perotenium through open infra umbilical port. Routine diagnostic laparoscopy was performed to check the primary port after creating another $10 \mathrm{~mm}$ epigastric port and $5 \mathrm{~mm}$ two secondary ports under vision. The gall bladder was thick walled and distended and was aspirated to reveal a mucocele. After careful dissection of calot's triangle and clipping of cystic duct and cystic artery the gall bladder was dissected from the liver using monopolar diathermy. The gall bladder was extracted through the umbilical port in a glove bag after dilating the port with scissors to facilitate delivery of the specimen. Hemostasis was secured, a RT drain (18G) drain placed, and all ports were examined for any bleeding as part of standard closure technique. The patient had uneventful recovery from anesthesia and remained hemodynamically stable until three hours later after which he drained $50 \mathrm{ml}$ of fresh blood followed by $300 \mathrm{ml}$ in the next 2 hours (Figure 1). Clinically, the only sign of volume loss was tachycardia (110/minute) with maintained blood pressure $(110 / 70 \mathrm{mmHg})$ and adequate urine output. 


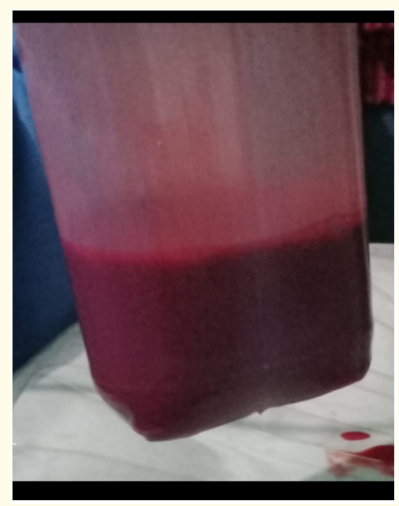

Figure 1: Fresh blood in drain bag.

Diagnostic Laparoscopy was carried out using the same ports except the one with drain in situ. It revealed large amount of blood and clots in the entire abdominal cavity including the pelvis, right and left para-colic gutter, over the omentum and sub hepatic area. No bleeding was seen at the operative site. Subsequently, the 10 $\mathrm{mm}$ telescope was transferred to the epigastric port when an arterial spurt was noticed near the umbilical port arising from a muscular twig of the inferior epigastric artery (IEA) (Figure 2). Another $10 \mathrm{~mm}$ port was created in the left hypocondrium to gain access and hemostasis was achieved using bipolar diathermy. The abdominal cavity was cleaned, all areas once again inspected and closure was performed.

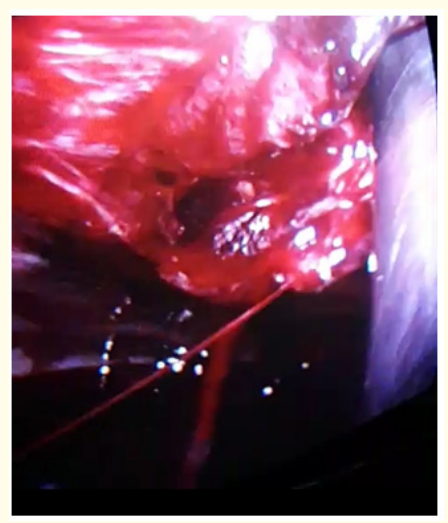

Figure 2: Aterial spurt from Inferior epigastric artery branch identified during re-laparoscopy.

Postoperatively, the patient remained stable. The drain was removed after 36 hours and the patient was discharged after $72 \mathrm{hrs}$.

\section{Discussion}

After anesthetic complications, vascular injuries are the most common cause for mortality and morbidity in laparoscopic surgery
[3]. Bleeding from the cystic artery, ligaments of liver, from the abdominal wall during the placement of ports are common sources of bleeding in these cases [4]. Despite taking appropriate precautions, vascular injuries secondary to port placement continue to get reported during laparoscopic cholecystectomy. The greatest risk of vascular injury however, lies during establishing the initial pneumoperitoneum either by veress needle or by variety of open access procedures as there is no universally correct method appropriate for all the patients [5-8]. In fact injury to the IEA is one of the most dangerous complications while creating pneumoperitoneum through infra or supra umbilical area. Various strategies such as direct optical access, high intraperitoneal pressure access, entry through the Palmer point in the left upper quadrant or by LeeHuang point in the middle upper abdomen have been practiced by some surgeons particularly in patients with prior lower abdominal surgery [9-11]. Besides, vascular injury may occur during ancillary port placement, which can be avoided by trans-illuminating the anterior abdominal wall and thus locating the IEA or superficial epigastric artery. However, transillumination technique is not effective in high BMI patients or in dark skinned persons $[12,13]$.

Further, the injury to the IEA during secondary port placement may be avoided by identifying a yellow island at the lateral third of the line joining anterior superior iliac spine (ASIS) and the umbilicus and guiding the trocar tip into a suction cannula put intraperitoneally through another port [14].

Bleeding may also happen during dissection, where bleeding from the cystic artery, right hepatic artery, IVC, omental vessels, mesentric vessels and liver bed bleeding have been reported. Nevertheless, post operative bleeding in LC is poorly documented where very few authors have actually described the incidence and its management and can be ascribed to publication bias. Injury to the inferior epigastric artery is extremely variable, and not uncommonly, its branches overlie the port placement area for laparoscopic cholecystectomy. Epigastric vessels are usually located between 4 and $8 \mathrm{~cm}$ from the midline but variability is not uncommon. Variability exists in the length, as well as the level at which it pierces the rectus abdominis [15]. As a result the rectus muscle should be avoided at all cost during port placements.

The unexpected anatomical course often predisposes this artery to be injured during port placement. Also, due to the tamponade effect of the trocar during the course of the procedure, coupled with an anesthetized patient with well controlled systemic blood pressure allows any bleeding vessel to go into spasm during inspection of the ports. This appears to be the most likely mechanism in our case where a higher blood pressure after extubation and discomfort opened up the branch. 
Early intervention is the key in these cases. Drainage of $350 \mathrm{ml}$ of blood in almost 2 hours was a giveaway in our case but in younger patients the only sign of volume loss might be tachycardia which is often ascribed to the patient being in pain. However, tachycardia due to pain is associated with hypertension.

\section{Conclusions}

Bleeding following laparoscopic cholecystectomy is uncommon but can potentially increase morbidity and mortality. Injury to the inferior epigastric artery during port placement is a known but under-reported event. Awareness of variability of the course of epigastric artery, ensuring that the systemic pressure is adequate during port inspection and having a high index of suspicion can contribute towards management of trocar related bleeding complications.

\section{Bibliography}

1. Philip A Philips and Joseph F Amaral "Abdominal access complications in laparoscopic surgery". Journal of the American College of Surgeons 192.4 (2001): 525-536.

2. Erol D., et al. "The Early Diagnosis And Treatment Of Acute Hemorrhagic Shock After Laparoscopic Cholecystectomy". The Internet Journal of Anesthesiology 9.2 (2004).

3. Gn M., et al. "Major complications during laparoscopic cholecystectomy”. International Surgery 92.3 (2007): 142-146.

4. Radunovic M., et al. "Complications of Laparoscopic Cholecystectomy: Our Experience from a Retrospective Analysis". Open Access Macedonian Journal of Medical Sciences. 4.4 (2016): 641-646.

5. Deffieux X., et al. "Risks associated with laparoscopic entry: guidelines for clinical practice from the French College of Gynaecologists and Obstetricians". European Journal of Obstetrics and Gynecology and Reproductive Biology 158.2 (2011): 159166.

6. Ahmad G., et al. "Laparoscopic entry techniques". Cochrane Database System Review (2008): CD006583.

7. Kaushik R. "Bleeding complications in laparoscopic cholecystectomy: Incidence, mechanisms, prevention and management". Journal of Minimal Access Surgery 6.3 (2010): 59-65.

8. Mases A., et al. "Injury to the Abdominal Aorta During Laparoscopic Surgery: An Unusual Presentation". Anesthesia and Analgesia 91.3 (2000): 561-562.
9. Tinelli A., et al. "Abdominal access in gynaecological laparoscopy: a comparison between direct optical and blind closed access by Verres needle". European Journal of Obstetrics and Gynecology and Reproductive Biology 148.2 (2010): 191-194.

10. Tinelli A., et al. "Laparoscopy entry in patients with previous abdominal and pelvic surgery". Surgical Innovation 18.3 (2011): 201-205.

11. Pickett SD., et al. "Avoiding major vessel injury during laparoscopic instrument insertion". Obstetrics and Gynecology Clinics of North America 37.3 (2010): 387-397.

12. Sandadi S., et al. "Recognition and management of major vessel injury during laparoscopy". Journal of Minimally Invasive Gynecology 17.6 (2010): 692-702.

13. Vilos GA., et al. "Laparoscopic entry: a review of techniques, technologies, and complications". Journal of Obstetrics and Gynaecology Canada 29.5 (2007): 433-447.

14. Tinelli A., et al. "Safe Introduction of Ancillary Trocars". JSLS 16.2 (2012): 276-279.

15. Manvikar Purushottam Rao., et al. "Study of the course of inferior epigastric artery with reference to laparoscopic portal". Journal of cited Minimally Invasive Gynecology 9.4 (2013): 154158.

\section{Assets from publication with us}

- Prompt Acknowledgement after receiving the article

- Thorough Double blinded peer review

- Rapid Publication

- Issue of Publication Certificate

- High visibility of your Published work

Website: www.actascientific.com/

Submit Article: www.actascientific.com/submission.php

Email us: editor@actascientific.com

Contact us: +919182824667

Citation: Urmila Basu., et al. "Injury to the Inferior Epigastric Artery Branch Necessitating Re-laparoscopy - An Unusual Cause of Bleeding in Laparoscopic Cholecystectomy". Acta Scientific Gastrointestinal Disorders 4.1 (2020): 03-05. 